Delamater Alan (Orcid ID: 0000-0003-2320-4164)

Malik Jamil (Orcid ID: 0000-0002-9521-4276)

Acerini Carlo (Orcid ID: 0000-0003-2121-5871)

ISPAD Clinical Practice Consensus Guidelines 2018

\title{
Psychological Care of Children and Adolescents with Type 1 Diabetes
}

\author{
Alan M. Delamater ${ }^{\mathrm{a}}$ \\ Maartje de Wit $^{\mathrm{b}}$ \\ Vincent McDarby ${ }^{c}$ \\ Jamil A. Malik ${ }^{d}$ \\ Marisa E. Hilliard ${ }^{\mathrm{e}}$ \\ Elisabeth Northam ${ }^{f}$ \\ Carlo L. Acerini ${ }^{\mathrm{g}}$
}

\begin{abstract}
${ }^{\text {a} D e p a r t m e n t ~ o f ~ P e d i a t r i c s, ~ U n i v e r s i t y ~ o f ~ M i a m i ~ M i l l e r ~ S c h o o l ~ o f ~ M e d i c i n e, ~ M i a m i, ~ U S A ~}$
${ }^{\mathrm{b}}$ Department of Medical Psychology, EMGO Institute for Health \& Care Research, VU University Medical Center Amsterdam, Netherlands

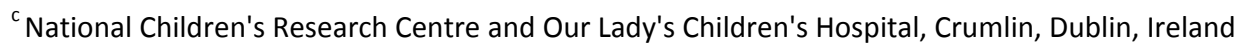

${ }^{d}$ National Institute of Psychology, Center of Excellence, Quaid-i-Azam University, Islamabad, Pakistan

e Department of Pediatrics, Baylor College of Medicine and Texas Children's Hospital, Houston, USA
\end{abstract}

This is the author manuscript accepted for publication and has undergone full peer review but has not been through the copyediting, typesetting, pagination and proofreading process, which may lead to differences between this version and the Version of Record. Please cite this article as doi: $10.1111 /$ pedi.12736

This article is protected by copyright. All rights reserved. 
fRoyal Children's Hospital, Victoria, Australia

${ }^{\mathrm{g}}$ Department of Paediatrics, University of Cambridge, UK

Corresponding author: Alan M. Delamater, PhD, adelamater@med.miami.edu

Conflicts of interest: The authors have declared no conflicts of interest

\section{Summary of What's New/Different}

Recent literature has been reviewed and new research findings as well as systematic reviews show the important role in management of type 1 diabetes in children and adolescents of:

1) Depression and diabetes distress;

2) Disordered eating behaviors;

3) Cognitive functioning and school performance;

4) Parental distress, coping, and demographic factors;

5) Stress and coping;

6) Factors affecting quality of life, including resiliency; and

7) Psychosocial and behavioral intervention studies to improve glycemic control, diabetes management behaviors, and psychosocial functioning.

\section{Executive Summary and Recommendations}

The following summary and recommendations build upon the previous ISPAD Guidelines (1) and are consistent with the latest statements and guidelines issued by the American Diabetes Association (2), Australia (APEG - Clinical Practice Guidelines, www.nhmrc.gov.au/publications/ pdf/cp102.pdf), Canada (www.diabetes.ca/cpg2003), and the UK (www.nice.org.uk/pdf/type1diabetes).

Young people with diabetes appear to have a greater incidence of depression, anxiety, psychological distress and eating disorders compared to their peers without diabetes (A). Children and young people with chronic poor metabolic control, including recurrent DKA, are more likely to have underlying psychosocial problems or psychiatric disorders than children in good metabolic control (A, B).

1. Resources should be made available to include professionals with expertise in the mental and behavioral health of children and adolescents within the interdisciplinary diabetes health care team. These mental health specialists should include psychologists, social workers, and psychiatrists (E).

Mental health professionals should be available to interact not only with patients and families at clinic visits to conduct screening and more complete assessments of psychosocial functioning, but also to support the diabetes team in the recognition and management of mental health and behavior 
problems $(A, E)$. There should a I so be easy access to consulting psychiatrists for cases involving severe psychopathology and the potential need for psychotropic medications (E). All mental and behavioral health specialists should have training in diabetes and its management (E).

2. The interdisciplinary diabetes health care team should maintain regular, consistent and uninterrupted contact with patients and their families. When clinic visits are missed or not frequent, other modes of contact should be made available such as by phone, SMS texting, or email (B, E).

3. Young people with diabetes are at increased risk for mild decrements in general cognitive ability, information processing skills, executive functions, and academic achievement, especially if there is a background of early diabetes onset, severe hypoglycemia or chronic hyperglycemia (B). Therefore, it is recommended that assessment of developmental progress in all domains of functioning (i.e., physical, intellectual, academic, emotional and social development) should be conducted on a routine basis ( $A$, $B, E)$.

- Quality of life can be reliably measured with good clinical utility (A).

- It is especially important to monitor the school performance of children who developed diabetes before age 5 years, and with a history of significant hypoglycemic episodes and/or chronic hyperglycemia at early ages (B).

- These children, as well as all children experiencing learning difficulties at school, should be referred for a psycho-educational or neuropsychological evaluation in order to determine if learning disabilities are present (B).

- Specific diabetes care plans should be formulated for the school setting and training conducted with school staff concerning diabetes management (B, E).

4. Routine assessment should be made of developmental adjustment to, and understanding of, diabetes management, including diabetes-related knowledge, insulin adjustment skills, goal setting, problem-solving abilities, regimen adherence, and self-management autonomy and competence. This is especially important during late childhood and prior to adolescence when in many families the child may take on diabetes management responsibilities without adequate maturity for effective self-management (B).

5. Identification of overall psychosocial well-being and diabetes-specific quality of life, as well as psychosocial adjustment problems, depression, eating disorders, diabetes distress, and other psychiatric disorders should be performed at planned intervals and by appropriately trained mental health professionals $(B, E)$. These assessments are particularly important in young people not achieving treatment goals or who exhibit chronically poor metabolic control. (B, E).

6. Several family factors including levels of family cohesion, agreement about diabetes management responsibilities, and levels of supportive and collaborative problem-solving behaviors influence treatment regimen adherence and glycemic control (B, C). Family conflict is associated with lower regimen adherence and poor glycemic control $(B, C)$. Therefore, the interdisciplinary team should assess general family functioning (conflict, cohesion, adaptability, parental psychopathology) and 
diabetes-related functioning (communication, parental involvement and support, roles and responsibilities for self-management behaviors) especially during periods of transition (e.g., at diagnosis, at start of a new treatment plan, early adolescence) and when there is evidence of cultural, language or family problems or difficulties in adjustment to diabetes $(A, B, E)$.

7. The interdisciplinary team should aim to provide preventive interventions for patients and families (including training parents in effective behavior management skills) at key developmental times, particularly after diagnosis and prior to adolescence $(A, E)$. These interventions should emphasize appropriate family involvement and support (i.e., teamwork) in diabetes management, effective problem-solving and self-management skills, and realistic expectations about glycemic control $(A, E)$.

8. Evidence-based psychosocial, behavioral, or psychiatric interventions should be made available for patients or families exhibiting conflict, disordered communication, diabetes distress, behavioral or psychiatric difficulties or adherence problems affecting glycemic control ( $, B, E)$. Developmental needs of children and adolescents should be considered while planning interventions incorporating social, emotional and tangible support (C, E).

9. In counseling young people and parents regarding advances in diabetes management, and encouraging the intensification of insulin regimens and use of advanced technologies, motivational interviewing may be useful (A). This may help in clarifying patient and parental goals and resolve ambivalence about regimen intensification. Patients should not be denied access to regimen intensification and advanced technologies based on perceptions of limited competence, as even youth with low self-management competence have been shown to improve with intensive insulin therapy $(A)$.

10. Adolescents should assume increasing responsibility for diabetes management tasks but with continuing, mutually agreed, parental involvement and support $(A, E)$. The transition to adult diabetes care should be discussed, negotiated and carefully planned with adolescents, their parents and the adult diabetes team well in advance of the actual transfer to adult care (E) (see guidelines on Adolescent Care).

\section{Introduction}

A substantial research base developed over the past thirty years provides evidence for the significant role of psychosocial factors in the management of type 1 diabetes (T1D) in children and adolescents (37). We review the main findings from studies of psychological adjustment, psychiatric disorders, neurocognitive and educational functioning, family dynamics, social support, stress and coping, quality of life, and behavioral interventions in children and adolescents with T1D. Based on these research findings, recommendations for optimal psychological care are offered, as detailed in the Executive Summary. 
The ISPAD Consensus Guidelines 2000 stated that "Psychosocial factors are the most important influences affecting the care and management of diabetes," and went on to make the following three general recommendations (8):

1. Social workers and psychologists should be part of the interdisciplinary health care team.

2. Overt psychological problems in young persons or family members should receive support from the diabetes care team and expert attention from mental health professionals.

3. The diabetes care team should receive training in the recognition, identification, and provision of information and counseling on psychosocial problems related to diabetes.

After reviewing the evidence base on psychological issues and interventions for children and adolescents with T1D, these general recommendations remain appropriate and are developed further with more specific recommendations for psychological care.

\section{Psychological Adjustment and Psychiatric Disorders}

Young people with diabetes appear to have a greater incidence of depression, anxiety, psychological distress and eating disorders compared to their healthy peers $(9,10)$. Research findings indicate children with T1D are at risk for adjustment problems during the initial period of adaptation after diagnosis (11, 12). When adjustment problems exist, children are at higher risk for continued adjustment difficulties (12-15) . In a ten-year prospective study from diagnosis of T1D, adolescents were at high risk for various psychiatric diagnoses; females were more likely than males to receive a diagnosis, and half of those with a history of poor glycemic control had a psychiatric diagnosis (16). However, a recent longitudinal study from adolescence into emerging adulthood did not reveal group differences in psychosocial adjustment $(17,18)$. More recent studies suggest differences between children with and without diabetes appear to be smaller (9). Nevertheless, about $15 \%$ of youth with diabetes report elevated levels of psychological distress, with potential negative consequences for self-management, and studies indicate behavioral problems are associated with poor glycemic control $(19,20)$.

Studies indicate that depression and anxiety are related with less frequent glucose monitoring and poorer glycemic control $(21,22)$. Results from the SEARCH study in the USA found that $14 \%$ percent of youth with diabetes reported mild depression and $8.6 \%$ reported moderate to severe depression; girls reported more depressive symptoms than boys, and depression was associated with poorer glycemic control and increased diabetes-related hospitalizations (23). A meta-analysis showed that depression is associated with poorer treatment adherence, and this association is even stronger in more recent studies; the association between depression and glycemic control is small to moderate, and smaller in more recent studies (24). Prospective studies indicate that greater depressive symptoms predict less frequent blood glucose monitoring, poorer quality of life, and poorer glycemic control over time (25, 26). Children with recurrent DKA are more likely to have psychiatric disorders than children in good glycemic control (27). Poor glycemic control has also been associated with a number of other 
psychosocial problems including anxiety (22), poor self-esteem, and diabetes distress (28, 29). Diabetes distress is common in adolescents with T1D and associated with decreased regimen adherence and poor health outcomes (30). When psychological adjustment problems persist into late adolescence, there is evidence indicating greater risk for poor diabetes management during early adulthood $(31,32)$. However, more research in this area is needed.

Youth that are depressed are also at an increased risk for disordered eating behaviors (e.g., restricting food intake and insulin omission) $(33,34)$. There is evidence that adolescents with diabetes, especially girls, have a higher incidence of disturbed eating behavior and eating disorders (10). It is estimated that $7 \%$ of adolescent girls with T1D may meet diagnostic criteria for an eating disorder, a rate twice as common as in girls without diabetes (10). Disordered eating behavior is more prevalent in adolescent girls with T1D (40\%) than their peers (33\%)(33). Results of a recent meta-analysis indicated that eating disorders are associated with poor glycemic control (10), although a recent longitudinal study did not show this association (33). Even at subclinical levels, glycemic control has been observed to worsen with increasing symptoms of eating disorder (35-37). Without intervention, disordered eating and insulin manipulation may worsen over time and increase the risk of serious health complications (38-40).

\section{Neurocognitive and School Functioning}

Subtle neurocognitive deficits (41-44) and pathological brain changes (45) have been documented in children and adolescents with TID. IQ scores are typically well within the average range but significantly lower than those of healthy controls. In a robust test of the impact of childhood onset diabetes on IQ, Lin et al. (46) calculated IQ change scores using measures obtained at diagnosis, and at follow up 12 years later, and showed a greater decline in Verbal and Full Scale IQ in participants with TID than was evident in the healthy controls. In addition to this difference in intellectual functioning, specific neurocognitive deficits have been documented in youth with TID. The specific skills most affected include information processing (attention, memory, processing speed) and executive skills (planning, organization problem solving, mental flexibility) $(41-43,47-50)$. It is important to note that intact information processing and executive skills are often required for disease management (51), thus possible weaknesses in these skills should be considered when children present with sub-optimal metabolic control.

Attempts to identify specific diabetes-related risk factors for neurocognitive sequelae in children with T1D have been a focus of much recent research. Meta-analytic and systematic reviews reveal a significant relationship between early disease onset and neurocognitive deficits $(42,43,52,53)$ with attention, memory/new learning and executive skills particularly affected in children who develop diabetes prior to $5-6$ years of age $(42,43,47,50)$. A positive history of hypoglycemia $(41,47,54)$ episodes of DKA (55) and chronic hyperglycemia $(43,47-50,56)$ have all been associated with neurocognitive deficits, albeit with some inconsistency in findings. The U-shaped relationship between blood glucose levels and neurocognitive performance demonstrated in field studies (57), difficulty in obtaining comprehensive, accurate, often retrospective accounts of metabolic control history, our inability to pinpoint the exact timing of putative neural insults as well as the fact that many children experience a combination of risk factors for neurocognitive sequelae have probably contributed to 
inconsistent findings. Current evidence is robust enough, though, to argue that optimal neuroprotection of the developing brain in children with T1D is achieved by meticulous avoidance of glycemic extremes.

Neurocognitive deficits in children with T1D are usually mild, but even subtle decrements can have an impact in children engaged in ongoing learning and skill development. There is evidence from both longitudinal cohort and population studies of poorer academic achievement (55-58) and lower rates employment post school $(58,59)$ in youth with TID. Children who develop diabetes prior to 6-7 years of age $(60)$ and those with a history of chronic hyperglycemia $(61,62)$ appear at particular risk of academic underachievement. Neurocognitive assessment, together with appropriate educational interventions, should be offered to all children with TID who present with unexplained academic underachievement or difficulties managing the problem solving demands inherent in optimal disease management.

The school setting also presents challenges for parents of a child with diabetes and they report considerable anxiety when their child is at school. Parents report feeling that schools are often not well informed about federal laws to accommodate their child with diabetes and believe that schools do not facilitate optimal treatment for their child (63). In describing school experiences of students with diabetes, better glycemic control and quality of life occurs when school personnel and friends receive some training in diabetes and its management (64).

\section{Family Functioning and Social Support}

The research literature has consistently demonstrated that family factors are integral to the management of diabetes in children $(7,65)$. Cross-sectional and prospective studies have shown that high levels of family cohesion, authoritative parenting, agreement about diabetes management responsibilities, supportive behaviors, parental monitoring of diabetes management, and collaborative problem-solving are associated with better regimen adherence and glycemic control, while family conflict, diffusion of responsibilities, and over- or under-involvement in diabetes management relative to the child's developmental level and abilities have been associated with worse regimen adherence and glycemic control (66-77). Family conflict and negative affect related to blood glucose monitoring have also been associated with depression (21). A collaborative parent-child relationship with shared responsibilities for diabetes management is associated not only with better regimen adherence but also with improved emotional functioning $(69,78,79)$. Socio-demographic family factors such as singleparent households or higher family density (more youth per adults in the household) (79-83), lower family income, and racial/ethnic minority status $(79,82-88)$ are associated with less optimal parental involvement in diabetes management and greater risk for poor control of diabetes.

It is important to note that many parents have psychological distress after the diagnosis of T1D in their children. One recent review indicated that on average $33.5 \%$ of parents report distress at diagnosis, with $19 \%$ of parents reporting distress one to four years after diagnosis (89); estimates of clinically elevated symptoms of depression and anxiety have been reported to be as high as $74 \%$ and $59 \%$, respectively, in the month following diagnosis (90). One study found that $24 \%$ of mothers and $22 \%$ of fathers met criteria for a diagnosis of post-traumatic stress disorder six weeks after their child had been diagnosed (91). Providing support to parents after the diagnosis of diabetes of their child is an important 
need and can promote better diabetes management $(92,93)$. Parental adjustment difficulties and stress have been related to lower parental self-efficacy for diabetes management and greater child behavior problems $(94,95)$. Another study found that psychological maladjustment of fathers predicted poor glycemic control in children five years after diagnosis (96). Fear of hypoglycemia has also been found to be common in parents of children with diabetes (97) and is associated with emotional distress and poorer glycemic control in children (98).

Social support from parents and other family members is especially important for children and adolescents with T1D. Research has shown that supportive cohesive families are more likely to have adolescents with improved adherence and metabolic control than families without such cohesion. Furthermore, adolescents with good adherence have interactions with their parents that are characterized as open and empathetic, whereas adolescents with poor adherence have interactions characterized as emotionally charged and confrontational $(99,100)$. It was also noted that levels of diabetes-specific family support were inversely related to youngsters' age, with older children and adolescents reporting significantly less family support for diabetes (100). Although the level of support provided by parents decreases as adolescents get older and take a greater degree of responsibility for their diabetes management, premature withdrawal of parental involvement is associated with poor diabetes outcomes, whereas continued parental support and monitoring is associated with better outcomes (101). It must be noted that while continued parental support in adolescent diabetes management may lead to better outcomes for adolescents, over-involvement by parents is associated with poorer metabolic control, and is a stronger predictor of metabolic control than age, gender, or insulin treatment regimen (76).

Social support from friends can be a unique source of support that complements parents' involvement and improves adolescents' diabetes management (101), with youths receiving instrumental support from their families and also considerable emotional support from their friends (102-106). When youth attribute negative peer reactions to their self-management, they are more likely to have adherence difficulties and increased diabetes stress, which in turn worsens glycemic control (107). Fear of stigmatization appears to be a barrier in acquiring support from peers (103). Poor peer relations has been associated with decreased regimen adherence and worse glycemic control over time, while more family support predicted better glycemic control (108). Overall, the research linking peer relations to diabetes outcomes is mixed. Although qualitative studies reveal that adolescents believe peers have an impact on their diabetes, the quantitative findings are inconclusive (109).

\section{Stress and Coping}

Considerable research has demonstrated the important role of stress and coping in predicting psychosocial adjustment and glycemic control among youth with T1D (110). Diabetes-related stress may have effects on the life of children and adolescents directly or indirectly. Using a direct approach, studies have shown that children with high life stress tend to have worse glycemic control $(28,107,111-115)$. Other research, using an indirect approach, found an adverse effect of diabetes stress on diabetes selfmanagement $(110,116,117)$. There is support from intervention studies targeting diabetes stress for improved glycemic control $(113,118)$. Daily stressors faced by younger children are usually related to 
friends/peers and siblings, and their coping behaviors include choosing an alternate activity and taking personal responsibility (119). Research examining coping styles has indicated that youths in poor metabolic control are more likely to use the learned helplessness style (120) and engage in avoidance coping and wishful thinking in response to stress $(121,122)$, while youths in good glycemic control have high levels of self-efficacy (123) and engage in active coping $(110,124-128)$. Longitudinal studies suggest a reciprocal relationship between active coping and better glycemic control $(125,129)$, while avoidance coping was linked with worse glycemic control and increased psychological stress (130, 131). Additionally, maladaptive coping in youth has also been associated with poor regimen adherence (132, 133). It has also been shown that resilience to stress is associated with better glycemic control (134, 135 ) and other diabetes outcomes including depressive symptoms, diabetes management, and quality of life $(126,136)$.

Research addressing the Health Belief Model in adolescents indicate that beliefs related to the seriousness of diabetes, personal vulnerability to complications, costs of regimen adherence, and beliefs in the efficacy of treatment/mediation beliefs, have been associated with both regimen adherence and glycemic control (137-140). Studies have also shown that individuals' personal models of illness belief for diabetes were associated with psychological adjustment and regimen adherence: greater impact of diabetes was related to increased anxiety, while beliefs about the effectiveness of treatment predicted better dietary self-management $(141,142)$. Personal model beliefs about diabetes were also shown to mediate the relationship between personality variables (emotional stability and conscientiousness) and self-management behaviors $(143,144)$. Studies of health risks associated with diabetes indicate that youth underestimate their own risks while acknowledging greater risks of diabetes attributed to other youths (145).

Identification and improvements in primary caregivers' (mostly mothers) coping may have the potential to improve both maternal and adolescent outcomes (146-151). Children with parents exhibiting the negotiator coping pattern had better glycemic control than children with parents classified as avoiders or doers (152). Research suggests that parental support groups may help parents cope more effectively in managing their children with T1D (153).

\section{Quality of Life}

Quality of life is recognized as a central outcome in diabetes care. In general, children with diabetes rate their own quality of life as similar to their healthy peers (154). However, parents tend to rate their child's quality of life somewhat lower, except for those 5-7 years of age (155-158). Boys tend to report better quality of life (159) as well as youth with longer diabetes duration and those from a better socioeconomic background $(154,158,160,161)$. Lower quality of life seems associated with psychiatric disorders, especially depression and anxiety $(162,163)$ and a negative family environment, especially diabetes conflicts (164). Less favorable quality of life also appears to be related with youths' perceptions that diabetes is upsetting, difficult to manage, and stressful, as well as fear of hypoglycemia $(164,165)$. There is some evidence that better quality of life is associated with better glycemic control, but the relationship between glycemic control and quality of life appears modest $(157,166-168)$. In a prospective study, poorer quality of life predicted subsequent poor glycemic control via less frequent 
blood glucose monitoring (169). Use of the insulin pump does not appear to adversely affect quality of life (170-172) and may be associated with improved quality of life. In addition, use of continuous glucose monitoring does not seem to adversely affect quality of life (173). A revised and updated measure of diabetes-specific quality of life has recently been shown to be reliable and valid for use in pediatric and adolescent patients with T1D, providing scores for diabetes symptoms and diabetes management (174). Research has shown that diabetes symptoms are associated with general health-related quality of life, which is partially mediated by diabetes management (175).

\section{Psychosocial and Behavioral Interventions}

Previous systematic reviews of the literature and meta-analysis (176-178) indicate that a number of controlled studies have shown the efficacy of psychosocial and behavioral interventions for children and adolescents with diabetes, although this literature is not without some methodological limitations $(4,5$, $176,179-182)$. Most of these interventions have included the family as an integral part of treatment (183).

The results of these studies indicate that family-based, behavioral procedures such as goal-setting, problem solving, self-monitoring, positive reinforcement, behavioral contracts, supportive parental communications, family restructuring, and appropriately shared responsibility for diabetes management have improved regimen adherence and glycemic control $(180,183,184)$. In addition, these interventions have improved the parent-adolescent relationship (180, 185-187), and improved regimen adherence $(177,187)$. Studies of behavioral family systems therapy with diabetes-specific tailoring targeting diabetes-specific behavioral problems, and training in behavioral contracting techniques have shown improvements in family conflict and regimen adherence (188) as well as improved glycemic control over 18 months (189). Controlled research has demonstrated this approach to improve parent-adolescent communication and problem solving which in turn was associated with improvements in glycemic control (190).

Given the crisis that diagnosis presents for children and families, the period just after diagnosis presents opportunities for intervention. Interdisciplinary intervention programs have been described and reported to improve outcomes (191-193). Psycho-educational interventions with children and their families that promote problem-solving skills and increase parental support early in the disease course have been shown to improve long-term glycemic control of children (194). Other trials involving psychosocial intervention after diagnosis showed improved family functioning without improved glycemic control $(195,196)$.

Research has shown that when parents allow older children and adolescents to have self-management autonomy without sufficient cognitive and social maturity, youths are more likely to have problems with diabetes management (197). Thus, a critical aspect of behavioral family management of diabetes is finding ways for parents and family members to remain involved and supportive, but not intrusive, in their children's daily care (198). A randomized controlled trial for positive parenting provides some support for improving parent and family outcomes, and reducing child internalizing and externalizing behavior problems (199). 
An intervention delivered during regular outpatient clinic visits and based on family-focused teamwork was shown to increase family involvement without causing family conflict or adversely affecting youth quality of life, and helped prevent worsening of glycemic control (200). A psycho-educational intervention addressing eight diabetes care issues (i.e., understanding $\mathrm{HbA1c}$, factors affecting blood sugars, the "blame and shame" cycle, a team approach to diabetes care, blood glucose monitoring, carbohydrate counting, research trends) delivered by a "care ambassador" at regular outpatient visits was shown to improve the frequency of outpatient visits, and reduced acute adverse outcomes such as hypoglycemia and emergency department visits (201).

Additional studies have been conducted on behavioral interventions integrated with outpatient medical clinic appointments. For example, monitoring and discussing quality of life issues with adolescent patients was found to improve psychosocial functioning over time (202). A recent randomized controlled trial showed little improvement in glycemic control yet significant improvement in psychosocial wellbeing as a result of a cognitive behavioral intervention program (203). A family-centered program integrated with routine clinic appointments led to improvements in glycemic control and parental involvement when families participated in two or more such sessions over the course of a 12 month follow-up. The program was designed to improve diabetes management by teaching problem-solving skills, communication skills, and appropriate responsibility sharing (204). In a large multi-site randomized trial, a family teamwork intervention delivered at the time of quarterly outpatient clinic visits led to improved glycemic control for young adolescents, but effects were not as strong for older children $(205,206)$.

Another approach utilized intensive home-based multi-systemic therapy with inner city adolescents in chronically poor metabolic control, a patient population that has not received much attention in the intervention literature. This approach incorporated interventions that encompasses the individual adolescent, the family system, and the broader community systems (i.e., school and health care system). Initial studies of this approach suggested it had potential to improve outcomes (207). The results of a larger randomized trial indicated this approach improved frequency of blood glucose monitoring, reduced inpatient admissions, improved glycemic control, and reduced medical costs $(208,209)$. Another study demonstrated reduced hospitalizations and costs for this high-risk group of adolescent patients using multi-systemic therapy (210).

Peer group interventions have also been evaluated. Results indicate that peer group support and problem-solving can improve short-term glycemic control (211). Group-based training in using effective coping skills improved glycemic control and quality of life for adolescents involved in intensive insulin regimens (212-214). Stress management, problem-solving and coping skills training delivered in small groups of youths has reduced diabetes-related stress $(215,216)$, improved social interaction $(217)$, and increased glucose monitoring and improved glycemic control (218).

Several studies have examined coping skills training with younger, school-age children. Results indicate this approach had some favorable effects on life satisfaction and family functioning (219). Although coping skills training for younger children was not shown to be more effective than an educational intervention, results from controlled studies do support the use of group interventions for children in 
this age range (220). Furthermore, coping skills training with parents of young children has also been shown to be helpful, although outcomes were not significantly different from the control group that received educational support (147).

It is important to maintain regular ongoing contact with families, as research findings indicate that children who have infrequent and irregular visits with the health care team are more likely to have glycemic control problems $(221,222)$. Research indicates that early adolescence represents a high risk time for diabetes management, with worsening of adherence observed over time (223), which may be due to decreased parental involvement.

Intrinsic motivation for diabetes management can be measured reliably and validly and has been shown to predict better diabetes management, glycemic control, and psychosocial functioning (224). Thus, increasing intrinsic motivation may be an effective way to improve regimen adherence and glycemic control in youth. Motivational interviewing appears to be a promising approach for adolescents, with initial studies showing improved glycemic control (225-227). A larger multi-center randomized trial demonstrated that motivational interviewing with adolescents improved long-term glycemic control and quality of life (228). Another study targeting motivation with an individualized personal trainer showed improved glycemic outcomes in older but not younger adolescents (229). It was demonstrated that this approach had long-term positive effects on glycemic control in older adolescents (230). However, in a recent multicenter study in which non-psychologist health care providers were trained in motivational interviewing, favorable effects on glycemic control were not observed (231), a finding which could be attributed to inadequate training and counseling skills of the health care staff (232). Meta-analytic reviews, however, support the use of motivational interviewing with various pediatric populations in terms of health outcomes $(232,233)$.

A recently reported large randomized controlled trial evaluated the effects of an 8-session, individuallydelivered distress and depression prevention program for adolescents with T1D. In this trial, a resilience program tailored to T1D was compared to an advanced diabetes education program. Results one year post-treatment demonstrated significant reductions in diabetes distress for adolescents in the resilience program, indicating that diabetes distress can be prevented in youth prior to symptoms of psychological distress (234).

Studies have also examined the use of the Internet to deliver behavioral interventions. For example, it was demonstrated that using an Internet program for diabetes problem-solving led to significant improvements in diabetes management and problem-solving, with stable glycemic control (235). This approach was particularly sensitive to diabetes management barriers with regard to social issues, time pressures, and dealing with emotions (236). Another study examined the effects of coping skills training for adolescents delivered over the Internet, compared with an Internet-delivered educational intervention. The results of this randomized controlled multi-site trial indicated clinical improvements for youth in both groups, supporting the concept that behavioral interventions can be effectively applied to youth with T1D using the Internet (237). 
A meta-analysis of intervention studies to promote regimen adherence in youth with T1D was conducted and found 15 studies that met criteria for analysis (238). While the results indicated small effect sizes for improvements in glycemic control, multi-component interventions addressing psychosocial and emotional processes had stronger effects. In a review of family-centered interventions, nine studies were examined and found that such interventions improve glycemic control and family functioning while reducing family conflict (239).

In summary, the results of controlled intervention research have shown that family-based interventions utilizing positive reinforcement and behavioral contracts, communication and problem-solving skills training, negotiation of diabetes management goals, and collaborative parental involvement have led not only to improved regimen behaviors and glycemic control, but also to improved family relationships. Group interventions for young people with diabetes targeting coping and stress management skills have also shown positive effects on regimen adherence, glycemic control, and quality of life. Individual interventions with adolescents have shown motivational interviewing approaches to improve glycemic control and psychosocial outcomes, although more evidence is needed. There is growing evidence supporting the use of the Internet to deliver behavioral interventions.

Support to Authors: Contribution of J.A Malik in preparation of manuscript is supported by grant no. 216/HEC/R\&D/PPCR/2017.

\section{References}

1. Delamater AM, de Wit M, McDarby V, Malik J, Acerini CL, International Society for P, et al. ISPAD Clinical Practice Consensus Guidelines 2014. Psychological care of children and adolescents with type 1 diabetes. Pediatr Diabetes. 2014;15 Suppl 20:232-44.

2. Young-Hyman D, de Groot M, Hill-Briggs F, Gonzalez JS, Hood K, Peyrot M. Psychosocial Care for People With Diabetes: A Position Statement of the American Diabetes Association. Diabetes care. 2016;39(12):2126-40.

3. Silverstein J, Klingensmith G, Copeland K, Plotnick L, Kaufman F, Laffel L, et al. Care of children and adolescents with type 1 diabetes: a statement of the American Diabetes Association. Diabetes Care. 2005;28(1):186-212.

4. Hampson SE, Skinner TC, Hart J, Storey L, Gage H, Foxcroft D, et al. Behavioral interventions for adolescents with type 1 diabetes: how effective are they? Diabetes Care. 2000;23(9):1416-22.

5. Winkley K, Landau S, Eisler I, Ismail K. Psychological interventions to improve glycaemic control in patients with type 1 diabetes: systematic review and meta-analysis of randomised controlled trials. BMJ. 2006;333(7558):65.

6. Laron Z, Galatzer A, Karger S. Psychological aspects of diabetes in children and adolescents. Pediatric and Adolescent Endocrinology. 1982;10:1-247.

7. Delamater AM. Psychological care of children and adolescents with diabetes. Pediatric Diabetes. 2009;10(s12):175-84.

8. ISPAD. Consensus Guidelines for the Management of Type 1 Diabetes Mellitus in Children and Adolescents. 2000. 
9. Reynolds K, Helgeson V. Children with Diabetes Compared to Peers: Depressed? Distressed? Annals of Behavioral Medicine. 2011;42(1):29-41.

10. Young V, Eiser C, Johnson B, Brierley S, Epton T, Elliott J, et al. Eating problems in adolescents with Type 1 diabetes: a systematic review with meta-analysis. Diabetic Medicine. 2013;30(2):189-98.

11. Kovacs M, Feinberg TL, Paulauskas S, Finkelstein R, Pollock M, Crouse-Novak M. Initial coping responses and psychosocial characteristics of children with insulin-dependent diabetes mellitus. The Journal of Pediatrics. 1985;106(5):827-34.

12. Grey M, Cameron ME, Lipman TH, Thurber FW. Psychosocial status of children with diabetes in the first 2 years after diagnosis. Diabetes care. 1995;18(10):1330-36.

13. Jacobson AM, Hauser ST, Lavori P, Willett JB, Cole CF, Wolfsdorf JI, et al. Family environment and glycemic control: a four-year prospective study of children and adolescents with insulin-dependent diabetes mellitus. Psychosomatic Medicine. 1994;56(5):401-09.

14. Kovacs $\mathrm{M}, \mathrm{Ho} \mathrm{V}$, Pollock MH. Criterion and predictive validity of the diagnosis of adjustment disorder: A prospective study of youths with new-onset insulin-dependent diabetes mellitus. 1995;152:523-28.

15. Schwartz DD, Cline VD, Axelrad ME, Anderson BJ. Feasibility, acceptability, and predictive validity of a psychosocial screening program for children and youth newly diagnosed with type 1 diabetes. Diabetes care. 2011;34(2):326-31.

16. Northam EA, Anderson PJ, Werther GA, Warne GL, Adler RG, Andrewes D. Neuropsychological complications of IDDM in children 2 years after disease onset. Diabetes care. 1998;21(3):379-84.

17. Helgeson VS, Snyder PR, Escobar O, Siminerio L, Becker D. Comparison of Adolescents with and without Diabetes on Indices of Psychosocial Functioning for Three Years. Journal of Pediatric Psychology. 2007;32(7):794-806.

18. Helgeson VS, Palladino DK, Reynolds KA, Becker DJ, Escobar O, Siminerio L. Relationships and health among emerging adults with and without Type 1 diabetes. Health Psychology. 2014;33(10):112533.

19. Naar-King S, Idalski A, Ellis D, Frey M, Templin T, Cunningham PB, et al. Gender Differences in Adherence and Metabolic Control in Urban Youth with Poorly Controlled Type 1 Diabetes: The Mediating Role of Mental Health Symptoms. Journal of Pediatric Psychology. 2006;31(8):793-802.

20. Holmes CS, Chen R, Streisand R, Marschall DE, Souter S, Swift EE, et al. Predictors of Youth Diabetes Care Behaviors and Metabolic Control: A Structural Equation Modeling Approach. Journal of Pediatric Psychology. 2006;31(8):770-84.

21. Hood KK, Huestis S, Maher A, Butler D, Volkening L, Laffel LMB. Depressive Symptoms in Children and Adolescents With Type 1 Diabetes: Association with diabetes-specific characteristics. Diabetes Care. 2006;29(6):1389.

22. Herzer M, Hood KK. Anxiety Symptoms in Adolescents with Type 1 Diabetes: Association with Blood Glucose Monitoring and Glycemic Control. Journal of Pediatric Psychology. 2010;35(4):415-25. 23. Lawrence JM, Standiford DA, Loots B, Klingensmith GJ, Williams DE, Ruggiero A, et al. Prevalence and Correlates of Depressed Mood Among Youth With Diabetes: The SEARCH for Diabetes in Youth Study. Pediatrics. 2006;117(4):1348-58. 
24. Kongkaew C, Jampachaisri K, Chaturongkul C, Scholfield CN. Depression and adherence to treatment in diabetic children and adolescents: a systematic review and meta-analysis of observational studies. European Journal of Pediatrics. 2014;173(2):203-12.

25. Hilliard ME, Herzer M, Dolan LM, Hood KK. Psychological screening in adolescents with type 1 diabetes predicts outcomes one year later. Diabetes Research and Clinical Practice. 2011;94(1):39-44.

26. Hilliard ME, Wu YP, Rausch J, Dolan L, Hood KK. Predictors of deteriorations in diabetes management and control in adolescents with type 1 diabetes Journal of Adolescent Health. 2013;52:2834.

27. Liss DS, Waller DA, Kennard BD, McIntire D, Capra P, Stephens J. Psychiatric Illness and Family Support in Children and Adolescents With Diabetic Ketoacidosis: A Controlled Study. Journal of the American Academy of Child \& Adolescent Psychiatry. 1998;37(5):536-44.

28. Delamater AM, Patiño-Fernández AM, Smith KE, Bubb J. Measurement of diabetes stress in older children and adolescents with type 1 diabetes mellitus. Pediatric Diabetes. 2013;14(1):50-56.

29. Malik JA, Koot HM. Explaining the adjustment of adolescents with type 1 diabetes: role of diabetes-specific and psychosocial factors. Diabetes care. 2009;32(5):774-79.

30. Hagger V, Hendrieckx C, Sturt J, Skinner TC, Speight J. Diabetes Distress Among Adolescents with Type 1 Diabetes: a Systematic Review. Curr Diab Rep. 2016;16(1):9.

31. Bryden KS, Peveler RC, Stein A, Neil A, Mayou RA, Dunger DB. Clinical and Psychological Course of Diabetes From Adolescence to Young Adulthood: A longitudinal cohort study. Diabetes Care. 2001;24(9):1536-40.

32. Wysocki T, Hough BS, Ward KM, Green LB. Diabetes Mellitus in the Transition to Adulthood: Adjustment, Self-Care, and Health Status. Journal of Developmental \& Behavioral Pediatrics. 1992;13(3):194-201.

33. Colton PA, Olmsted MP, Daneman D, Rodin GM. Depression, disturbed eating behavior, and metabolic control in teenage girls with type 1 diabetes. Pediatric Diabetes. 2013;14(5):372-76.

34. Eisenberg Colman MH, Quick VM, Lipsky LM, Dempster KW, Liu A, Laffel LMB, et al. Disordered Eating Behaviors Are Not Increased by an Intervention to Improve Diet Quality but Are Associated With Poorer Glycemic Control Among Youth With Type 1 Diabetes. Diabetes care. 2018;41(4):869-75.

35. Bryden KS, Neil A, Mayou RA, Peveler RC, Fairburn CG, Dunger DB. Eating habits, body weight, and insulin misuse. A longitudinal study of teenagers and young adults with type 1 diabetes. Diabetes Care. 1999;22(12):1956-60.

36. Meltzer LJ, Johnson SB, Prine JM, Banks RA, Desrosiers PM, Silverstein JH. Disordered Eating, Body Mass, and Glycemic Control in Adolescents With Type 1 Diabetes. Diabetes Care. 2001;24(4):67882.

37. Wisting L, Frøisland DH, Skrivarhaug T, Dahl-Jørgensen $K, R \varnothing \varnothing$. Disturbed eating behavior and omission of insulin in adolescents receiving intensified insulin treatment: a nationwide population-based study. Diabetes care. 2013;36(11):3382-87.

38. Rydall AC, Rodin GM, Olmsted MP, Devenyi RG, Daneman D. Disordered Eating Behavior and Microvascular Complications in Young Women with Insulin-Dependent Diabetes Mellitus. New England Journal of Medicine. 1997;336(26):1849-54.

39. Goebel-Fabbri AE, Fikkan J, Franko DL, Pearson K, Anderson BJ, Weinger K. Insulin restriction and associated morbidity and mortality in women with type 1 diabetes. Diabetes care. 2008;31(3):415-19. 
40. Young-Hyman DL, Davis CL. Disordered eating behavior in individuals with diabetes importance of context, evaluation, and classification. Diabetes Care. 2010;33(3):683-89.

41. Naguib JM, Kulinskaya E, Lomax CL, Garralda ME. Neuro-cognitive performance in children with type 1 diabetes - a meta-analysis. Journal of Pediatric Psychology. 2008;34(3):271-82.

42. Gaudieri PA, Chen R, Greer TF, Holmes CS. Cognitive function in children with type 1 diabetes: a meta-analysis. Diabetes care. 2008;31(9):1892-97.

43. Tonoli C, Heyman E, Roelands B, Pattyn N, Buyse L, Piacentini MF, et al. Type 1 diabetesassociated cognitive decline: A meta-analysis and update of the current literature. Journal of diabetes. 2014;6(6):499-513.

44. McNeilly AD, McCrimmon RJ. The Scylla and Charybdis of glucose control in childhood type 1 diabetes? Pediatric Diabetes. 2015;16(4):235-41.

45. Arbelaez AM, Semenkovich K, Hershey T. Glycemic extremes in youth with T1DM: the structural and functional integrity of the developing brain. Pediatric Diabetes. 2013;14(8):541-53.

46. Lin A, Northam EA, Werther GA, Cameron FJ. Risk factors for decline in IQ in youth with type 1 diabetes over the 12 years from diagnosis/illness onset. Diabetes care. 2015;38(2):236-42.

47. Lin A, Northam EA, Rankins D, Werther GA, Cameron FJ. Neuropsychological profiles of young people with type 1 diabetes 12 yr after disease onset. Pediatric Diabetes. 2010;11(4):235-43.

48. Patiño-Fernández AM, Delamater AM, Applegate EB, Brady E, Eidson M, Nemery R, et al. Neurocognitive functioning in preschool-age children with type 1 diabetes mellitus. Pediatric Diabetes. 2010;11(6):424-30.

49. Cato MA, Mauras N, Ambrosino J, Bondurant A, Conrad AL, Kollman C, et al. Cognitive functioning in young children with type 1 diabetes. Journal of the International Neuropsychological Society. 2014;20(2):238-47.

50. Kaufmann L, Pixner S, Starke M, Zotter S, Kohle J, Meraner D, et al. Neurocognition and brain structure in pediatric patients with type 1 diabetes. Journal of Pediatric Neuroradiology. 2012;1(1):2535.

51. McNally K, Rohan J, Pendley JS, Delamater A, Drotar D. Executive functioning, treatment adherence, and glycemic control in children with type 1 diabetes. Diabetes care. 2010;33(6):1159-62.

52. Northam EA, Rankins D, Cameron FJ. Therapy insight: the impact of type 1 diabetes on brain development and function. Nature Reviews Neurology. 2006;2(2):78.

53. Desrocher M, Rovet J. Neurocognitive correlates of type 1 diabetes mellitus in childhood. Child Neuropsychology. 2004;10(1):36-52.

54. Blasetti A, Chiuri RM, Tocco AM, Giulio CD, Mattei PA, Ballone E, et al. The effect of recurrent severe hypoglycemia on cognitive performance in children with type 1 diabetes: a meta-analysis. Journal of child neurology. 2011;26(11):1383-91.

55. Cameron FJ, Scratch SE, Nadebaum C, Northam EA, Koves I, Jennings J, et al. Neurological consequences of diabetic ketoacidosis at initial presentation of type 1 diabetes in a prospective cohort study of children. Diabetes care. 2014;37(6):1554-62.

56. Aye T, Reiss AL, Kesler S, Hoang S, Drobny J, Park Y, et al. The feasibility of detecting neuropsychologic and neuroanatomic effects of type 1 diabetes in young children. Diabetes care. 2011;34(7):1458-62. 
57. Gonder-Frederick LA, Zrebiec JF, Bauchowitz AU, Ritterband L, Magee JC, Cox DJ, et al. Cognitive Function Is Disrupted by Both Hypo-and Hyperglycemia in School-AgedChildren With Type 1 Diabetes: A Field Study. Diabetes care. 2009;32(6):1001-06.

58. Northam EA, Lin A, Finch S, Werther GA, Cameron FJ. Psychosocial well-being and functional outcomes in youth with type 1 diabetes 12 years after disease onset. Diabetes care. 2010;33(7):1430-37. 59. Persson S, Dahlquist G, Gerdtham U-G, Carlsson KS. Impact of childhood-onset type 1 diabetes on schooling: a population-based register study. Diabetologia. 2013;56(6):1254-62.

60. Dahlquist G, Källén B, Group SCDS. School performance in children with type 1 diabetes-a population-based register study. Diabetologia. 2007;50(5):957-64.

61. Hannonen R, Komulainen J, Riikonen R, Ahonen T, Eklund K, Tolvanen A, et al. Academic skills in children with early-onset type 1 diabetes: the effects of diabetes-related risk factors. Developmental Medicine \& Child Neurology. 2012;54(5):457-63.

62. Cooper MN, McNamara KA, de Klerk NH, Davis EA, Jones TW. School performance in children with type 1 diabetes: a contemporary population-based study. Pediatric Diabetes. 2016;17(2):101-11. 63. Jacquez F, Stout S, Alvarez-Salvat R, Fernandez M, Villa M, Sanchez J, et al. Parent perspectives of diabetes management in schools. The Diabetes Educator. 2008;34(6):996-1003.

64. Wagner J, Heapy A, James A, Abbott G. Brief Report: Glycemic Control, Quality of Life, and School Experiences Among Students with Diabetes. Journal of Pediatric Psychology. 2006;31(8):764-69.

65. Jaser SS. Family Interaction in Pediatric Diabetes. Current Diabetes Reports. 2011;11(6):480-85.

66. Tsiouli E, Alexopoulos EC, Stefanaki C, Darviri C, Chrousos GP. Effects of diabetes-related family stress on glycemic control in young patients with type 1 diabetes: Systematic review. Canadian Family Physician. 2013;59(2):143-49.

67. Davis CL, Delamater AM, Shaw KH, La Greca AM, Eidson MS, Perez-Rodriguez JE, et al. Parenting Styles, Regimen Adherence, and Glycemic Control in 4- to 10-Year-Old Children With Diabetes. Journal of Pediatric Psychology. 2001;26(2):123-29.

68. Wysocki T, lannotti R, Weissberg-Benchell J, Laffel L, Hood K, Anderson B, et al. Diabetes Problem Solving by Youths with Type 1 Diabetes and their Caregivers: Measurement, Validation, and Longitudinal Associations with Glycemic Control. Journal of Pediatric Psychology. 2008;33(8):875-84.

69. Helgeson VS, Reynolds KA, Siminerio L, Escobar O, Becker D. Parent and Adolescent Distribution of Responsibility for Diabetes Self-care: Links to Health Outcomes. Journal of Pediatric Psychology. 2008;33(5):497-508.

70. Wysocki T, Nansel TR, Holmbeck GN, Chen R, Laffel L, Anderson BJ, et al. Collaborative involvement of primary and secondary caregivers: associations with youths' diabetes outcomes. J Pediatr Psychol. 2009;34(8):869-81.

71. Hilliard ME, Holmes CS, Chen R, Maher K, Robinson E, Streisand R. Disentangling the roles of parental monitoring and family conflict in adolescents' management of type 1 diabetes. Health Psychology. 2013;32(4):388-96.

72. Sood ED, Pendley JS, Delamater AM, Rohan JM, Pulgaron ER, Drotar D. Mother-father informant discrepancies regarding diabetes management: Associations with diabetes-specific family conflict and glycemic control. Health Psychology. 2012;31(5):571-79. 
73. Shorer M, David R, Schoenberg-Taz M, Levavi-Lavi I, Phillip M, Meyerovitch J. Role of parenting style in achieving metabolic control in adolescents with type 1 diabetes. Diabetes care. 2011;34(8):173537.

74. Robinson EM, Weaver P, Chen R, Streisand R, Holmes CS. A model of parental distress and factors that mediate its link with parental monitoring of youth diabetes care, adherence, and glycemic control. Health Psychology. 2016;35(12):1373-82.

75. Hilliard ME, Wu YP, Rausch J, Dolan LM, Hood KK. Predictors of deteriorations in diabetes management and control in adolescents with type 1 diabetes. Journal of Adolescent Health. 2013;52(1):28-34.

76. Cameron FJ, Skinner T, De Beaufort C, Hoey H, Swift PG, Aanstoot H, et al. Are family factors universally related to metabolic outcomes in adolescents with Type 1 diabetes? Diabetic medicine. 2008;25(4):463-68.

77. Rohan JM, Rausch JR, Pendley JS, Delamater AM, Dolan L, Reeves G, et al. Identification and prediction of group-based glycemic control trajectories during the transition to adolescence. Health Psychology. 2014;33(10):1143.

78. Berg CA, Schindler I, Maharajh S. Adolescents' and mothers' perceptions of the cognitive and relational functions of collaboration and adjustment in dealing with type 1 diabetes. Journal of Family Psychology. 2008;22(6):865-74.

79. Lord JH, Young MT, Gruhn MA, Grey M, Delamater AM, Jaser SS. Effect of Race and Marital Status on Mothers' Observed Parenting and Adolescent Adjustment in Youth With Type 1 Diabetes. Journal of Pediatric Psychology. 2015;40(1):132-43.

80. Forsander GA, Sundelin J, Persson B. Influence of the initial management regimen and family social situation on glycemic control and medical care in children with type I diabetes mellitus. Acta Pædiatrica. 2000;89(12):1462-68.

81. Thompson SJ, Auslander WF, White NH. Comparison of Single-Mother and Two-Parent Families on Metabolic Control of Children With Diabetes. Diabetes Care. 2001;24(2):234-38.

82. Caccavale $L$, Weaver $P$, Chen R, Streisand R, Holmes CS. Family density and SES related to diabetes management and glycemic control in adolescents with type 1 diabetes. Journal of Pediatric Psychology. 2015;40(5):500-08.

83. Helgeson VS, Vaughn AK, Seltman H, Orchard T, Libman I, Becker D. Featured Article:

Trajectories of Glycemic Control Over Adolescence and Emerging Adulthood: An 11-Year Longitudinal Study of Youth With Type 1 Diabetes. Journal of Pediatric Psychology. 2017;43(1):8-18.

84. Delamater AM, Shaw KH, Applegate EB, Pratt IA, Eidson M, Lancelotta GX, et al. Risk for metabolic control problems in minority youth with diabetes. Diabetes Care. 1999;22(5):700-05.

85. Gallegos-Macias AR, Macias SR, Kaufman E, Skipper B, Kalishman N. Relationship between glycemic control, ethnicity and socioeconomic status in Hispanic and white non-Hispanic youths with type 1 diabetes mellitus. Pediatric Diabetes. 2003;4(1):19-23.

86. Petitti DB, Klingensmith GJ, Bell RA, Andrews JS, Dabelea D, Imperatore G, et al. Glycemic Control in Youth with Diabetes: The SEARCH for Diabetes in Youth Study. The Journal of Pediatrics. 2009;155(5):668-72.e3. 
87. Cengiz E, Xing D, Wong JC, Wolfsdorf JI, Haymond MW, Rewers A, et al. Severe hypoglycemia and diabetic ketoacidosis among youth with type 1 diabetes in the T1D Exchange clinic registry. Pediatric Diabetes. 2013;14(6):447-54.

88. Redondo MJ, Connor CG, Ruedy KJ, Beck RW, Kollman C, Wood JR, et al. Pediatric diabetes consortium type 1 diabetes New Onset (NeOn) study: factors associated with HbA1c levels one year after diagnosis. Pediatric Diabetes. 2014;15(4):294-302.

89. Whittemore R, Jaser S, Chao A, Jang M, Grey M. Psychological experience of parents of children with type 1 diabetes: a systematic mixed-studies review. The Diabetes Educator. 2012;38(4):562-79.

90. Streisand R, Mackey ER, Elliot BM, Mednick L, Slaughter IM, Turek J, et al. Parental anxiety and depression associated with caring for a child newly diagnosed with type 1 diabetes: opportunities for education and counseling. Patient Education and Counseling. 2008;73(2):333-38.

91. Landolt MA, Ribi K, Laimbacher J, Vollrath M, Gnehm HE, Sennhauser FH. Brief Report:

Posttraumatic Stress Disorder in Parents of Children With Newly Diagnosed Type 1 Diabetes. Journal of Pediatric Psychology. 2002;27(7):647-52.

92. Sullivan-Bolyai S, Bova C, Leung K, Trudeau A, Lee M, Gruppuso P. Social Support to Empower Parents (STEP): An Intervention for Parents of Young Children Newly Diagnosed With Type 1 Diabetes. The Diabetes Educator. 2010;36(1):88-97.

93. Carcone Al, Ellis DA, Weisz A, Naar-King S. Social support for diabetes illness management: supporting adolescents and caregivers. Journal of developmental and behavioral pediatrics: JDBP. 2011;32(8):581.

94. Hilliard M, Monaghan M, Cogen F, Streisand R. Parent stress and child behaviour among young children with type 1 diabetes. Child: care, health and development. 2011;37(2):224-32.

95. Lohan A, Morawska A, Mitchell A. Associations Between Parental Factors and Child DiabetesManagement-Related Behaviors. Journal of Developmental \& Behavioral Pediatrics. 2017;38(5):330-38. 96. Forsander G, Persson B, Sundelin J, Berglund E, Snellman K, Hellstrom R. Metabolic control in children with insulin-dependent diabetes mellitus $5 y$ after diagnosis. Early detection of patients at risk for poor metabolic control. Acta Pædiatrica. 1998;87(8):857-64.

97. Barnard K, Thomas S, Royle P, Noyes K, Waugh N. Fear of hypoglycaemia in parents of young children with type 1 diabetes: a systematic review. BMC pediatrics. 2010;10(1):50.

98. Haugstvedt A, Wentzel-Larsen T, Graue M, Søvik O, Rokne B. Fear of hypoglycaemia in mothers and fathers of children with Type 1 diabetes is associated with poor glycaemic control and parental emotional distress: a population-based study. Diabetic Medicine. 2010;27(1):72-78.

99. Burroughs TE, Harris MA, Pontious SL, Santiago JV. Research on social support in adolescents with IDDM: a critical review. Diabetes Educ. 1997;23(4):438-48.

100. La Greca AM, Auslander WF, Greco P, Spetter D, Fisher Jr EB, Santiago JV. I get by with a little help from my family and friends: Adolescents' support for diabetes care. Journal of Pediatric Psychology. 1995;20(4):449-76.

101. Wysocki T, Greco P. Social support and diabetes management in childhood and adolescence: influence of parents and friends. Curr Diab Rep. 2006;6(2):117-22.

102. La Greca AM, Auslander WF, Greco P, Spetter D, Fisher EB, Santiago JV. I Get by with a Little Help from my Family and Friends: Adolescents' Support for Diabetes Care. Journal of Pediatric Psychology. 1995;20(4):449-76. 
103. Peters LW, Nawijn L, van Kesteren N. How adolescents with diabetes experience social support from friends: two qualitative studies. Scientifica. 2014;2014.

104. Malik JA, Koot HM. Assessing diabetes support in adolescents: factor structure of the Modified Diabetes Social Support Questionnaire (M-DSSQ-Family). Pediatric Diabetes. 2011;12(3pt2):258-65.

105. Malik JA, Koot HM. Assessing diabetes support in adolescents: factor structure of the modified Diabetes Social Support Questionnaire (DSSQ-Friends). Diabetic Medicine. 2012;29(8):e232-e40.

106. La Greca AM, Bearman KJ. The Diabetes Social Support Questionnaire-Family Version: Evaluating Adolescents' Diabetes-Specific Support From Family Members. Journal of Pediatric Psychology. 2002;27(8):665-76.

107. Hains AA, Berlin KS, Hobart Davies W, Smothers MK, Sato AF, Alemzadeh R. Attributions of Adolescents with Type 1 Diabetes Related to Performing Diabetes Care around Friends and Peers: The Moderating Role of Friend Support. Journal of Pediatric Psychology. 2007;32(5):561-70.

108. Helgeson VS, Siminerio L, Escobar O, Becker D. Predictors of Metabolic Control among Adolescents with Diabetes: A 4-Year Longitudinal Study. Journal of Pediatric Psychology. 2009;34(3):25470.

109. Palladino DK, Helgeson VS. Friends or foes? A review of peer influence on self-care and glycemic control in adolescents with type 1 diabetes. J Pediatr Psychol. 2012;37(5):591-603.

110. Jaser SS, Patel N, Xu M, Tamborlane WV, Grey M. Stress and Coping Predicts Adjustment and Glycemic Control in Adolescents with Type 1 Diabetes. Ann Behav Med. 2017;51(1):30-38.

111. Hanson SL, Pichert JW. Perceived stress and diabetes control in adolescents. Health Psychology. 1986;5(5):439-52.

112. Worrall-Davies A, Holland P, Berg I, Goodyer I. The effect of adverse life events on glycaemic control in children with insulin dependent diabetes mellitus. European Child \& Adolescent Psychiatry. 1999;8(1):11-16.

113. Saghaei M, Omidi P, Dehkordi EH, Safavi P. The effectiveness of cognitive-function stress management training in glycemic control in children and in mental health of mother caring for child with type 1 diabetes mellitus. Diabetes Metab Syndr. 2017;10.1016/j.dsx.2017.07.017.

114. Gever LN. Coping with complications of diabetes. Nursing. 1986;16(5):74-9.

115. Peyrot M, McMurry JF, Jr., Kruger DF. A biopsychosocial model of glycemic control in diabetes: stress, coping and regimen adherence. J Health Soc Behav. 1999;40(2):141-58.

116. Nomura M, Fujimoto K, Higashino A, Denzumi M, Miyagawa M, Miyajima $H$, et al. Stress and coping behavior in patients with diabetes mellitus. Acta Diabetol. 2000;37(2):61-4.

117. Malik JA, Batool A, Nawaz A. Feedback Loop between Diabetes Management and Quality of Life: A Synthesis of Direct and Indirect Effects. Pakistan Journal of Medical Research. 2016;55(4):103.

118. Karlsen B, Idsoe T, Dirdal I, Rokne Hanestad B, Bru E. Effects of a group-based counselling programme on diabetes-related stress, coping, psychological well-being and metabolic control in adults with type 1 or type 2 diabetes. Patient Educ Couns. 2004;53(3):299-308.

119. Hema DA, Roper SO, Nehring JW, Call A, Mandleco BL, Dyches TT. Daily stressors and coping responses of children and adolescents with type 1 diabetes. Child: care, health and development. 2009;35(3):330-39.

120. Kuttner MJ, Delamater AM, Santiago JV. Learned Helplessness in Diabetic Youths. Journal of Pediatric Psychology. 1990;15(5):581-94. 
121. Delamater AM, Kurtz SM, Bubb J, White NH, Santiago JV. Stress and Coping in Relation to Metabolic Control of Adolescents with Type 1 Diabetes. Journal of Developmental \& Behavioral Pediatrics. 1987;8(3):136-40.

122. Hapunda G, Abubakar A, van de Vijver F, Pouwer F. Living with type 1 diabetes is challenging for Zambian adolescents: qualitative data on stress, coping with stress and quality of care and life. BMC Endocr Disord. 2015;15:20.

123. Grossman HY, Brink S, Hauser ST. Self-efficacy in adolescent girls and boys with insulindependent diabetes mellitus. Diabetes care. 1987;10(3):324-29.

124. Graue M, Wentzel-Larsen T, Bru E, Hanestad BR, Søvik O. The coping styles of adolescents with type 1 diabetes are associated with degree of metabolic control. Diabetes care. 2004;27(6):1313-17.

125. Luyckx K, Seiffge-Krenke I, Hampson SE. Glycemic Control, Coping, and Internalizing and Externalizing Symptoms in Adolescents With Type 1 Diabetes A cross-lagged longitudinal approach. Diabetes Care. 2010;33(7):1424-29.

126. Yi-Frazier JP, Yaptangco M, Semana S, Buscaino E, Thompson V, Cochrane K, et al. The association of personal resilience with stress, coping, and diabetes outcomes in adolescents with type 1 diabetes: Variable- and person-focused approaches. . Journal of health psychology. 2013.

127. Van Bussel A, Nieuwesteeg A, Janssen E, van Bakel H, Van den Bergh B, Maas-van Schaaijk N, et al. Goal disturbance and coping in children with type I diabetes mellitus: relationships with healthrelated auality of life and A1C. Canadian journal of diabetes. 2013;37(3):169-74.

128. Skočić M, Rudan V, Brajković L, Marčinko D. Relationship among psychopathological dimensions, coping mechanisms, and glycemic control in a Croatian sample of adolescents with diabetes mellitus type 1. European child \& adolescent psychiatry. 2010;19(6):525-33.

129. Rassart J, Luyckx K, Oris L, Goethals E, Moons P, Weets I. Coping with type 1 diabetes through emerging adulthood: Longitudinal associations with perceived control and haemoglobin A1c. Psychol Health. 2016;31(5):622-35.

130. Iturralde E, Weissberg-Benchell J, Hood KK. Avoidant coping and diabetes-related distress: Pathways to adolescents' Type 1 diabetes outcomes. Health Psychol. 2017;36(3):236-44.

131. Kraaij V, Garnefski N. Cognitive, behavioral and goal adjustment coping and depressive symptoms in young people with diabetes: a search for intervention targets for coping skills training. J Clin Psychol Med Settings. 2015;22(1):45-53.

132. Albai A, Sima A, Papava I, Roman D, Andor B, Gafencu M. Association between coping mechanisms and adherence to diabetes-related self-care activities: a cross-sectional study. Patient Prefer Adherence. 2017;11:1235-41.

133. Hanson CL, Cigrang JA, Harris MA, Carle DL, Relyea G, Burghen GA. Coping styles in youths with insulin-dependent diabetes mellitus. J Consult Clin Psychol. 1989;57(5):644-51.

134. Crump C, Sundquist J, Winkleby MA, Sundquist K. Stress resilience and subsequent risk of type 2 diabetes in 1.5 million young men. Diabetologia. 2016;59(4):728-33.

135. Yi-Frazier JP, Yaptangco M, Semana S, Buscaino E, Thompson V, Cochrane K, et al. The association of personal resilience with stress, coping, and diabetes outcomes in adolescents with type 1 diabetes: variable- and person-focused approaches. J Health Psychol. 2015;20(9):1196-206.

136. Jaser S, White L. Coping and resilience in adolescents with type 1 diabetes. Child: care, health and development. 2011;37(3):335-42. 
137. Bond GG, Aiken LS, Somerville SC. The health belief model and adolescents with insulindependent diabetes mellitus. Health Psychology. 1992;11(3):190-98.

138. Brownlee-Duffeck M, Peterson L, Simonds JF, Goldstein D, Kilo C, Hoette S. The role of health beliefs in the regimen adherence and metabolic control of adolescents and adults with diabetes mellitus. Journal of Consulting and Clinical Psychology. 1987;55(2):139-44.

139. Palardy N, Greening L, Ott J, Holderby A, Atchison J. Adolescents' Health Attitudes and Adherence to Treatment for Insulin-Dependent Diabetes Mellitus. Journal of Developmental \& Behavioral Pediatrics. 1998;19(1):31-37.

140. De Villiers FP. The poor children of the poor: Coping with diabetes control in a resource-poor setting. S Afr Med J. 2015;105(5):397-9.

141. Skinner TC, Hampson SE. Personal Models of Diabetes in Relation to Self-Care, Well-Being, and Glycemic Control: A prospective study in adolescence. Diabetes Care. 2001;24(5):828-33.

142. Mumtaz T, Haider SA, Malik JA, La Greca AM. Translation, validation and effectiveness of selfcare inventory in assessing adherence to diabetes treatment. J Pak Med Assoc. 2016;66(7):853-8.

143. Skinner TC, Hampson SE, Fife-Schaw C. Personality, personal model beliefs, and self-care in adolescents and young adults with Type 1 diabetes. Health Psychol. 2002;21(1):61-70.

144. Rassart J, Luyckx K, Klimstra TA, Moons P, Groven C, Weets I. Personality and illness adaptation in adults with type 1 diabetes: the intervening role of illness coping and perceptions. J Clin Psychol Med Settings. 2014;21(1):41-55.

145. Patino AM, Sanchez J, Eidson M, Delamater AM. Health Beliefs and Regimen Adherence in Minority Adolescents with Type 1 Diabetes. Journal of Pediatric Psychology. 2005;30(6):503-12.

146. Grey M. Coping and psychosocial adjustment in mothers of young children with type 1 diabetes. Journal of the Association for the Care of Children's Health. 2009;38(2):91-106.

147. Grey M, Jaser SS, Whittemore R, Jeon S, Lindemann E. Coping skills training for parents of children with type 1 diabetes: 12-month outcomes. Nursing research. 2011;60(3):173.

148. Jaser SS, Linsky R, Grey M. Coping and psychological distress in mothers of adolescents with type 1 diabetes. Maternal and child health journal. 2014;18(1):101-08.

149. Pisula E, Czaplinska C. Coping with stress in adolescents with type 1 diabetes and their mothers. European journal of medical research. 2010;15:115-19.

150. Streisand R, Mackey ER, Herge W. Associations of parent coping, stress, and well-being in mothers of children with diabetes: Examination of data from a national sample. Maternal and child health journal. 2010;14(4):612-17.

151. Grover S, Bhadada S, Kate N, Sarkar S, Bhansali A, Avasthi A, et al. Coping and caregiving experience of parents of children and adolescents with type-1 diabetes: An exploratory study. Perspect Clin Res. 2016;7(1):32-9.

152. Korner A, Wurz J, Brosseau DC, Brahler E, Kapellen T, Kiess W. Parental dyadic coping in families of children and adolescents with type 1 diabetes. Journal of pediatric endocrinology \& metabolism. 2013;26(9-10):867-75.

153. Pate T, Rutar M, Battelino T, Drobnic Radobuljac M, Bratina N. Support Group for Parents Coping with Children with Type 1 Diabetes. Zdr Varst. 2015;54(2):79-85.

154. Nieuwesteeg A, Pouwer F, van der Kamp R, van Bakel H, Aanstoot H-J, Hartman E. Quality of life of children with type 1 diabetes: a systematic review. Current diabetes reviews. 2012;8(6):434-43. 
155. Varni JW, Burwinkle TM, Jacobs JR, Gottschalk M, Kaufman F, Jones KL. The PedsQL' ${ }^{\mathrm{TM}}$ in Type 1 and Type 2 Diabetes: Reliability and validity of the Pediatric Quality of Life Inventory ${ }^{\text {TM }}$ Generic Core Scales and Type 1 Diabetes Module. Diabetes Care. 2003;26(3):631-37.

156. Upton $\mathrm{P}$, Eiser $\mathrm{C}$, Cheung I, Hutchings $\mathrm{H}$, Jenney $\mathrm{M}$, Maddocks $\mathrm{A}$, et al. Measurement properties of the UK-English version of the Pediatric Quality of Life InventoryTM 4.0 (PedsQLTM) generic core scales. Health and Quality of Life Outcomes. 2005;3(1):22.

157. Hesketh KD, Wake MA, Cameron FJ. Health-Related Quality of Life and Metabolic Control in Children With Type 1 Diabetes: A prospective cohort study. Diabetes Care. 2004;27(2):415-20.

158. Yi-Frazier JP, Hilliard ME, Fino NF, Naughton MJ, Liese AD, Hockett CW, et al. Whose quality of life is it anyway? Discrepancies between youth and parent health-related quality of life ratings in type 1 and type 2 diabetes. Qual Life Res. 2016;25(5):1113-21.

159. Anderson BJ, Laffel LM, Domenger C, Danne T, Phillip M, Mazza C, et al. Factors associated with diabetes-specific health-related quality of life in youth with type 1 diabetes: the Global TEENs Study. Diabetes care. 2017;40(8):1002-09.

160. Wake M, Hesketh K, Cameron F. The Child Health Questionnaire in children with diabetes: crosssectional survey of parent and adolescent-reported functional health status. Diabetic Medicine.

2000;17(10):700-07.

161. Hassan K, Loar R, Anderson BJ, Heptulla RA. The role of socioeconomic status, depression, quality of life, and glycemic control in type 1 diabetes mellitus. The Journal of Pediatrics.

2006;149(4):526-31.

162. Lawrence JM, Yi-Frazier JP, Black MH, Anderson A, Hood K, Imperatore G, et al. Demographic and Clinical Correlates of Diabetes-Related Quality of Life among Youth with Type 1 Diabetes. The Journal of Pediatrics. 2012;161(2):201-07.e2.

163. Butwicka A, Fendler W, Zalepa A, Szadkowska A, Zawodniak-Szalapska M, Gmitrowicz A, et al. Psychiatric disorders and health-related quality of life in children with type 1 diabetes mellitus. Psychosomatics. 2016;57(2):185-93.

164. Laffel LM, Connell A, Vangsness L, Goebel-Fabbri A, Mansfield A, Anderson BJ. General Quality of Life in Youth With Type 1 Diabetes Relationship to patient management and diabetes-specific family conflict. Diabetes Care. 2003;26(11):3067-73.

165. Johnson S, Cooper M, Davis E, Jones T. Hypoglycaemia, fear of hypoglycaemia and quality of life in children with Type 1 diabetes and their parents. Diabetic medicine. 2013;30(9):1126-31.

166. Grey M, Boland EA, Yu C, Sullivan-Bolyai S, Tamborlane WV. Personal and family factors associated with quality of life in adolescents with diabetes. Diabetes care. 1998;21(6):909-14.

167. Guttmann-Bauman I, Flaherty BP, Strugger M, McEvoy RC. Metabolic control and quality-of-life self-assessment in adolescents with IDDM. Diabetes care. 1998;21(6):915-18.

168. Hoey H, Aanstoot H-J, Chiarelli F, Daneman D, Danne T, Dorchy H, et al. Good Metabolic Control Is Associated With Better Quality of Life in 2,101 Adolescents With Type 1 Diabetes. Diabetes Care. 2001;24(11):1923-28.

169. Hilliard ME, Mann KA, Peugh JL, Hood KK. How poorer quality of life in adolescence predicts subsequent type 1 diabetes management and control. Patient Education and Counseling. 2013;91(1):120-25. 
170. Frøisland DH, Graue M, Markestad T, Skrivarhaug T, Wentzel-Larsen T, Dahl-Jørgensen K. Healthrelated quality of life among Norwegian children and adolescents with type 1 diabetes on intensive insulin treatment: a population-based study. Acta Paediatrica. 2013;102(9):889-95.

171. Wagner V, Müller-Godeffroy E, Sengbusch S, Häger S, Thyen U. Age, metabolic control and type of insulin regime influences health-related quality of life in children and adolescents with type 1 diabetes mellitus. European Journal of Pediatrics. 2005;164(8):491-96.

172. Valenzuela JM, Patino AM, McCullough J, Ring C, Sanchez J, Eidson M, et al. Insulin Pump Therapy and Health-Related Quality of Life in Children and Adolescents with Type 1 Diabetes. Journal of Pediatric Psychology. 2006;31(6):650-60.

173. Group JDRFCGMS. Quality-of-life measures in children and adults with type 1 diabetes: Juvenile Diabetes Research Foundation Continuous Glucose Monitoring randomized trial. Diabetes care. 2010;33(10):2175-77.

174. Varni JW, Delamater AM, Hood KK, Raymond JK, Chang NT, Driscoll KA, et al. PedsQL 3.2 Diabetes Module for children, adolescents, and young adults: Reliability and validity in type 1 diabetes. Diabetes care. In Press.

175. Varni JW, Delamater AM, Hood KK, Driscoll KA, Wong JC, Adi S, et al. Diabetes management mediating effects between diabetes symptoms and health-related quality of life in adolescents and young adults with type 1 diabetes. Pediatric Diabetes. 2018;10.1111/pedi.12713.

176. Ayling K, Brierley S, Johnson B, Heller S, Eiser C. Efficacy of theory-based interventions for young people with type 1 diabetes: a systematic review and meta-analysis. Br J Health Psychol. 2015;20(2):42846.

177. Viana LV, Gomes MB, Zajdenverg L, Pavin EJ, Azevedo MJ, Brazilian Type 1 Diabetes Study G. Interventions to improve patients' compliance with therapies aimed at lowering glycated hemoglobin (HbA1c) in type 1 diabetes: systematic review and meta-analyses of randomized controlled clinical trials of psychological, telecare, and educational interventions. Trials. 2016;17:94.

178. Quirk H, Blake H, Tennyson R, Randell TL, Glazebrook C. Physical activity interventions in children and young people with Type 1 diabetes mellitus: a systematic review with meta-analysis. Diabet Med. 2014;31(10):1163-73.

179. Hampson SE, Skinner TC, Hart J, Storey L, Gage H, Foxcroft D, et al. Effects of educational and psychosocial interventions for adolescents with diabetes mellitus: a systematic review. Health Technol Assess. 2001;5(10):1-79.

180. Murphy HR, Rayman G, Skinner TC. Psycho-educational interventions for children and young people with Type 1 diabetes. Diabet Med. 2006;23(9):935-43.

181. Delamater AM, Jacobson AM, Anderson B, Cox D, Fisher L, Lustman P, et al. Psychosocial Therapies in Diabetes: Report of the Psychosocial Therapies Working Group. Diabetes Care. 2001;24(7):1286-92.

182. Raymond J. Updates in behavioural and psychosocial literature in adolescents with type 1 diabetes. Curr Opin Endocrinol Diabetes Obes. 2015;22(4):265-9.

183. Feldman MA, Anderson LM, Shapiro JB, Jedraszko AM, Evans M, Weil LEG, et al. Family-Based Interventions Targeting Improvements in Health and Family Outcomes of Children and Adolescents with Type 1 Diabetes: a Systematic Review. Curr Diab Rep. 2018;18(3):15. 
184. Anderson BJ, Brackett J, Ho J, Laffel LM. An office-based intervention to maintain parentadolescent teamwork in diabetes management. Impact on parent involvement, family conflict, and subsequent glycemic control. Diabetes Care. 1999;22(5):713-21.

185. Wysocki T, Miller KM, Greco P, Harris MA, Harvey LM, Taylor A, et al. Behavior therapy for families of adolescents with diabetes: Effects on directly observed family interactions. Behavior Therapy. 1999;30(3):507-25.

186. Wysocki T, Harris MA, Greco P, Bubb J, Danda CE, Harvey LM, et al. Randomized, Controlled Trial of Behavior Therapy for Families of Adolescents With Insulin-Dependent Diabetes Mellitus. Journal of Pediatric Psychology. 2000;25(1):23-33.

187. Wysocki T, Greco P, Harris MA, Bubb J, White NH. Behavior Therapy for Families of Adolescents With Diabetes: Maintenance of treatment effects. Diabetes Care. 2001;24(3):441-46.

188. Wysocki T, Harris MA, Buckloh LM, Mertlich D, Lochrie AS, Taylor A, et al. Effects of Behavioral Family Systems Therapy for Diabetes on Adolescents' Family Relationships, Treatment Adherence, and Metabolic Control. Journal of Pediatric Psychology. 2006;31(9):928-38.

189. Wysocki T, Harris MA, Buckloh LM, Mertlich D, Lochrie AS, Mauras N, et al. Randomized Trial of Behavioral Family Systems Therapy for Diabetes: Maintenance of effects on diabetes outcomes in adolescents. Diabetes Care. 2007;30(3):555-60.

190. Wysocki T, Harris MA, Buckloh LM, Mertlich D, Lochrie AS, Taylor A, et al. Randomized, Controlled Trial of Behavioral Family Systems Therapy for Diabetes: Maintenance and Generalization of Effects on Parent-Adolescent Communication. Behavior Therapy. 2008;39(1):33-46.

191. Laron Z, Galatzer A, Amir S, Gil R, Karp M, Mimouni M. A multidisciplinary, comprehensive, ambulatory treatment scheme for diabetes mellitus in children. Diabetes care. 1979;2(4):342-48.

192. Galatzer A, Amir S, Gil R, Karp M, Laron Z. Crisis intervention program in newly diagnosed diabetic children. Diabetes care. 1982;5(4):414-19.

193. Goldberg A, Wiseman H. Parents' sense of coherence and the adolescent's health and emotional and behavioral adjustment: the case of adolescents with diabetes. J Pediatr Nurs. 2014;29(5):e15-21.

194. Delamater AM, Bubb J, Davis SG, Smith JA, Schmidt L, White NH, et al. Randomized prospective study of self-management training with newly diagnosed diabetic children. Diabetes care. 1990;13(5):492-98.

195. Sundelin J, Forsander G, Mattson SE. Family-oriented support at the onset of diabetes mellitus: a comparison of two group conditions during 2 years following diagnosis. Acta Paediatr. 1996;85(1):49-55. 196. Sullivan-Bolyai S, Grey M, Deatrick J, Gruppuso P, Giraitis P, Tamborlane W. Helping other mothers effectively work at raising young children with type 1 diabetes. Diabetes Educ. 2004;30(3):47684.

197. Wysocki T, Taylor A, Hough BS, Linscheid TR, Yeates KO, Naglieri JA. Deviation from developmentally appropriate self-care autonomy: association with diabetes outcomes. Diabetes care. 1996;19(2):119-25.

198. Babler E, Strickland CJ. Moving the Journey Towards Independence: Adolescents Transitioning to Successful Diabetes Self-Management. J Pediatr Nurs. 2015;30(5):648-60.

199. Westrupp EM, Northam E, Lee KJ, Scratch SE, Cameron F. Reducing and preventing internalizing and externalizing behavior problems in children with type 1 diabetes: a randomized controlled trial of the Triple P-Positive Parenting Program. Pediatr Diabetes. 2015;16(7):554-63. 
200. Laffel LMB, Vangsness L, Connell A, Goebel-Fabbri A, Butler D, Anderson BJ. Impact of ambulatory, family-focused teamwork intervention on glycemic control in youth with type 1 diabetes. The Journal of Pediatrics. 2003;142(4):409-16.

201. Svoren BM, Butler D, Levine B-S, Anderson BJ, Laffel LMB. Reducing Acute Adverse Outcomes in Youths With Type 1 Diabetes: A Randomized, Controlled Trial. Pediatrics. 2003;112(4):914-22.

202. de Wit M, Delemarre-van de Waal HA, Bokma JA, Haasnoot K, Houdijk MC, Gemke RJ, et al. Monitoring and Discussing Health-Related Quality of Life in Adolescents With Type 1 Diabetes Improve Psychosocial Well-Being: A randomized controlled trial. Diabetes Care. 2008;31(8):1521-26.

203. Serlachius AS, Scratch SE, Northam EA, Frydenberg E, Lee KJ, Cameron FJ. A randomized controlled trial of cognitive behaviour therapy to improve glycaemic control and psychosocial wellbeing in adolescents with type 1 diabetes. J Health Psychol. 2016;21(6):1157-69.

204. Murphy HR, Wadham C, Rayman G, Skinner TC. Approaches to integrating paediatric diabetes care and structured education: experiences from the Families, Adolescents, and Children's Teamwork Study (FACTS). Diabetic Medicine. 2007;24(11):1261-68.

205. Nansel TR, Anderson BJ, Laffel LMB, Simons-Morton BG, Weissberg-Benchell J, Wysocki T, et al. A multisite trial of a clinic-integrated intervention for promoting family management of pediatric type 1 diabetes: feasibility and design. Pediatric Diabetes. 2009;10(2):105-15.

206. Nansel TR, lannotti RJ, Liu A. Clinic-Integrated Behavioral Intervention for Families of Youth With Type 1 Diabetes: Randomized Clinical Trial. Pediatrics. 2012;129(4):e866-e73.

207. Harris MA, Mertlich D. Piloting Home-Based Behavioral Family Systems Therapy for Adolescents With Poorly Controlled Diabetes. Children's Health Care. 2003;32(1):65-79.

208. Ellis DA, Frey MA, Naar-King S, Templin T, Cunningham P, Cakan N. Use of Multisystemic Therapy to Improve Regimen Adherence Among Adolescents With Type 1 Diabetes in Chronic Poor Metabolic Control: A randomized controlled trial. Diabetes Care. 2005;28(7):1604-10.

209. Ellis DA, Naar-King S, Frey M, Templin T, Rowland M, Cakan N. Multisystemic Treatment of Poorly Controlled Type 1 Diabetes: Effects on Medical Resource Utilization. Journal of Pediatric Psychology. 2005;30(8):656-66.

210. Ellis D, Naar-King S, Templin T, Frey M, Cunningham P, Sheidow A, et al. Multisystemic therapy for adolescents with poorly controlled type 1 diabetes: reduced diabetic ketoacidosis admissions and related costs over 24 months. Diabetes care. 2008;31(9):1746-47.

211. Anderson BJ, Wolf FM, Burkhart MT, Cornell RG, Bacon GE. Effects of peer-group intervention on metabolic control of adolescents with IDDM: Randomized outpatient study. Diabetes care. 1989;12(3):179-83.

212. Boland EA, Grey M, Oesterle A, Fredrickson L, Tamborlane WV. Continuous subcutaneous insulin infusion. A new way to lower risk of severe hypoglycemia, improve metabolic control, and enhance coping in adolescents with type 1 diabetes. Diabetes care. 1999;22(11):1779-84.

213. Grey M, Boland EA, Davidson M, Yu C, Sullivan-Bolyai S, Tamborlane WV. Short-term effects of coping skills training as adjunct to intensive therapy in adolescents. Diabetes care. 1998;21(6):902-08. 214. Grey M, Boland EA, Davidson M, Li J, Tamborlane WV. Coping skills training for youth with diabetes mellitus has long-lasting effects on metabolic control and quality of life. The Journal of Pediatrics. 2000;137(1):107-13. 
215. Boardway RH, Delamater AM, Tomakowsky J, Gutai JP. Stress Management Training for Adolescents with Diabetes. Journal of Pediatric Psychology. 1993;18(1):29-45.

216. Hains AA, Davies WH, Parton E, Totka J, Amoroso-Camarata J. A Stress Management Intervention for Adolescents With Type I Diabetes. The Diabetes Educator. 2000;26(3):417-24.

217. Méndez FJ, Beléndez M. Effects of a behavioral intervention on treatment adherence and stress management in adolescents with IDDM. Diabetes care. 1997;20(9):1370-75.

218. Cook S, Herold K, Edidin DV, Briars R. Increasing Problem Solving in Adolescents With Type 1 Diabetes: The Choices Diabetes Program. The Diabetes Educator. 2002;28(1):115-24.

219. Ambrosino JM, Fennie K, Whittemore R, Jaser S, Dowd MF, Grey M. Short-term effects of coping skills training in school-age children with type 1 diabetes. Pediatric Diabetes. 2008;9(3pt2):74-82.

220. Grey M, Whittemore R, Jaser S, Ambrosino J, Lindemann E, Liberti L, et al. Effects of coping skills training in school-age children with type 1 diabetes. Research in nursing \& health. 2009;32(4):405-18.

221. Jacobson AM, Hauser ST, Willett J, Wolfsdorf JI, Herman L. Consequences of irregular versus continuous medical follow-up in children and adolescents with insulin-dependent diabetes mellitus. The Journal of Pediatrics. 1997;131(5):727-33.

222. Kaufman FR, Halvorson M, Carpenter S. Association between diabetes control and visits to a multidisciplinary pediatric diabetes clinic. Pediatrics. 1999;103(5):948-51.

223. Johnson SB, Kelly M, Henretta JC, Cunningham WR, Tomer A, Silverstein JH. A Longitudinal Analysis of Adherence and Health Status in Childhood Diabetes. Journal of Pediatric Psychology. 1992;17(5):537-53.

224. Delamater AM, Daigre AL, Marchante AN, Pulgarón ER, Patiño-Fernandez AM, Sanchez J. Intrinsic motivation in ethnic minority youth with type 1 diabetes. Children's Health Care. 2017;46(3):215-29.

225. Viner RM, Christie D, Taylor V, Hey S. Motivational/solution-focused intervention improves HbA1c in adolescents with Type 1 diabetes: a pilot study. Diabetic Medicine. 2003;20(9):739-42.

226. Channon S, Smith VJ, Gregory JW. A pilot study of motivational interviewing in adolescents with diabetes. Archives of Disease in Childhood. 2003;88(8):680-83.

227. Stanger C, Ryan SR, Delhey LM, Thrailkill K, Li Z, Li Z, et al. A multicomponent motivational intervention to improve adherence among adolescents with poorly controlled type 1 diabetes: a pilot study. J Pediatr Psychol. 2013;38(6):629-37.

228. Channon SJ, Huws-Thomas MV, Rollnick S, Hood K, Cannings-John RL, Rogers C, et al. A Multicenter Randomized Controlled Trial of Motivational Interviewing in Teenagers With Diabetes. Diabetes Care. 2007;30(6):1390-95.

229. Nansel TR, lannotti RJ, Simons-Morton BG, Cox C, Plotnick LP, Clark LM, et al. Diabetes personal trainer outcomes: short-term and 1-year outcomes of a diabetes personal trainer intervention among youth with type 1 diabetes. Diabetes Care. 2007;30(10):2471-7.

230. Nansel TR, lannotti RJ, Simons-Morton BG, Plotnick LP, Clark LM, Zeitzoff L. Long-Term Maintenance of Treatment Outcomes: Diabetes Personal Trainer Intervention for Youth With Type 1 Diabetes. Diabetes Care. 2009;32(5):807-09.

231. Robling M, McNamara R, Bennert K, Butler CC, Channon S, Cohen D, et al. The effect of the Talking Diabetes consulting skills intervention on glycaemic control and quality of life in children with type 1 diabetes: cluster randomised controlled trial (DEPICTED study). Bmj. 2012;344:e2359. 
232. Gayes LA, Steele RG. A meta-analysis of motivational interviewing interventions for pediatric health behavior change. J Consult Clin Psychol. 2014;82(3):521-35.

233. Borrelli B, Tooley EM, Scott-Sheldon LA. Motivational Interviewing for Parent-child Health Interventions: A Systematic Review and Meta-Analysis. Pediatr Dent. 2015;37(3):254-65.

234. Hood KK, Iturralde E, Rausch J, Weissberg-Benchell J. Preventing Diabetes Distress in Adolescents With Type 1 Diabetes: Results One Year After Participation in the STePS Program. Diabetes care. 2018;10.2337/dc17-2556.

235. Mulvaney SA, Rothman RL, Wallston KA, Lybarger C, Dietrich MS. An Internet-Based Program to Improve Self-Management in Adolescents With Type 1 Diabetes. Diabetes Care. 2010;33(3):602-04.

236. Mulvaney SA, Rothman RL, Osborn CY, Lybarger C, Dietrich MS, Wallston KA. Self-management problem solving for adolescents with type 1 diabetes: Intervention processes associated with an Internet program. Patient Education and Counseling. 2011;85(2):140-42.

237. Grey M, Whittemore R, Jeon S, Murphy K, Faulkner MS, Delamater AM. Internet psychoeducation programs improve outcomes in for youth with type 1 diabetes. Diabetes Care. 2013;36:247582.

238. Hood KK, Rohan JM, Peterson CM, Drotar D. Interventions With Adherence-Promoting Components in Pediatric Type 1 Diabetes: Meta-analysis of their impact on glycemic control. Diabetes Care. 2010;33(7):1658-64.

239. McBroom LA, Enriquez M. Review of Family-centered Interventions to Enhance the Health Outcomes of Children With Type 1 Diabetes. The Diabetes Educator. 2009;35(3):428-38. 


\section{University Library}

\section{- M I N E R VA}

\section{A gateway to Melbourne's research publications}

Minerva Access is the Institutional Repository of The University of Melbourne

Author/s:

Delamater, AM;de Wit, M;McDarby, V;Malik, JA;Hilliard, ME;Northam, E;Acerini, CL

Title:

ISPAD Clinical Practice Consensus Guidelines 2018: Psychological care of children and adolescents with type 1 diabetes

Date:

2018-10-01

\section{Citation:}

Delamater, A. M., de Wit, M., McDarby, V., Malik, J. A., Hilliard, M. E., Northam, E. \& Acerini, C. L. (2018). ISPAD Clinical Practice Consensus Guidelines 2018: Psychological care of children and adolescents with type 1 diabetes. PEDIATRIC DIABETES, 19, pp.237-249. https://doi.org/10.1111/pedi.12736.

Persistent Link:

http://hdl.handle.net/11343/284563 